\title{
Design and Synthesis of Two Azetidin-haloperidol Derivatives using Some Strategies
}

\author{
FIGUEROA-VALVERDE LAURO ${ }^{*}$, DÍAZ-CEDILLO FRANCISCO², \\ GARCÍA-CERVERA ELODIA', POOL-GÓMEZ EDUARDO', \\ LÓPEZ-RAMOS MARIA ${ }^{1}$, ROSAS-NEXTICAPA MARCELA ${ }^{3}$, HAU-HEREDIA LENIN ${ }^{1}$ and \\ SARABIA-ALCOCER BEATRIZ ${ }^{4}$
}
${ }^{1}$ Laboratory of Pharmaco-Chemistry, Faculty of Chemical Biological Sciences, University Autonomous of Campeche, Av. Agustín Melgar s/n, Col Buenavista C.P.24039 Campeche Cam., México.
Escuela Nacional de Ciencias Biológicas del Instituto Politécnico Nacional. Prol. Carpio y Plan de Ayala s/n Col. Santo Tomas, México, D.F. C.P. 11340.
${ }^{3}$ Facultad de Nutrición, Universidad Veracruzana, Médicos y Odontologos s/n C.P. 91010, Unidad del Bosque Xalapa Veracruz, México.
${ }^{4}$ Faculty of Medicine, University Autonomous of Campeche, Av. Patricio Trueba de Regil s/n, ColLindavista C.P.24090 Campeche Cam., México.
*Correspondence author E-mail: lauro_1999@yahoo.com

http://dx.doi.org/10.13005/ojc/300305

(Received: March 16, 2014; Accepted: April 25, 2014)

\begin{abstract}
In this study is reported a straight forward route for synthesis of two azetidin-haloperidol derivatives using some strategies. The first stage was achieved by the synthesis of an azetidine derivative (3) by the reaction of a haloperidol derivative (1) with chloroacetyl chloride in presence oftriethylamine. The second stage was achieved by reaction of an estradiol derivative with 1 to forma haloperidol-estradiol derivative (5) using boric acid as catalyst. Finally, the third stage involves the synthesis of a second azetidine-derivative (6) by the reaction of 5 with chloroacetyl chloride usingtriethylamine as catalyst. The structure of the compounds obtained was confirmed by elemental analysis, spectroscopy and spectrometry data. The proposed method offers some advantages such as simple procedure, low cost, and ease of workup.
\end{abstract}

Key words: Azetidin-haloperidol derivatives, Elemental analysis, Spectroscopy.

\section{INTRODUCTION}

Since several years ago, have been prepared some azetidine derivatives using different methods. For example, the synthesis of 1,2,4-trisubstituted azetidines by reductive cyclization of aza-Michael adducts of chalcones ${ }^{1}$. Other study ${ }^{2}$ showed the preparation of N-Benzyl3-hydroxyazetidine by the reaction of N-Benzyl-3chloro-2-hydroxypropylamine with $\mathrm{NaHCO}_{3}$ in $\mathrm{MeCN}$. 
In addition, other data indicate the synthesis of azetidine-2,3-diones by mild hydrolysis of the product of the reaction between $\alpha$-phenylthio- $\beta$-lactams and sulfuryl chloride ${ }^{3}$. Other report showed the synthesis of (2R,4S)-3-methyl-2,4-diphenylazetidine by the reaction of (2S,3S)-3-amino-2-methyl-1,3-diphenylpropan-1-ol with $\mathrm{Et}_{3} \mathrm{~N}$ and $\mathrm{MsCl}$ in basic medium ${ }^{4}$.Additionaly, a study shown the synthesis of trans-I-(Diphenylmethyl)2-methyl-3-azetidinol by the reaction of threo-3-bromo1,2 -epoxybutane with diphenylmethylamine ${ }^{5}$. Also other report indicate the preparation of 2-[22 -\{42 2 -substituted aryl-32 2 -chloro-22 2 -oxo-azetidine\}acetyl amino]-4-phenyl-1,3-thiazole by the reaction of 2-(22 -Arylidene-hydrazino-acetyl)-amino-4-phenyl1,3-thiazole with chloroacetyl chloride in presence of triethylamine ${ }^{6}$. Additionally, a study showed the synthesis of N-phenyl-3,3-dimethyl-azetidine-2,4-dione by reaction of phenylisocyanate with isobutyryl chloride using triethylamine as catalyst ${ }^{7}$. All these experimental results show several procedures which are available for synthesis of several azetidine derivatives; nevertheless, expensive reagents and special conditions are required. Therefore, in this study two azetidin-haloperidol derivatives were synthetized using some strategies.

\section{EXPERIMENTAL}

The compound 1-[4-(2-Amino-ethylimino)4-(4-fluorocyclohexyl)-butyl]-4-(4-chlorophenyl)-piperidin-4-ol (1) and 3,17-Dihydroxy-13methyl-7,8,9,11,12,13,14, 15,16,17-decahydro-6Hcyclopenta [a]phenanthrene-2,4-dicarbaldehyde (4) were prepared according to previously reported method $^{8,9}$. The other compounds evaluated in this study were purchased from Sigma-Aldrich Co. Ltd. The melting points for the different compounds were determined on an Electrothermal (900 model). Infrared spectra (IR) were recorded using $\mathrm{KBr}$ pellets on a Perkin Elmer Lambda 40 spectrometer. ${ }^{1} \mathrm{H}$ and ${ }^{13} \mathrm{C}$ NMR spectra were recorded on a Varian VXR-300/5 FT NMR spectrometer at 300 and $75.4 \mathrm{MHz}$ in $\mathrm{CDCl}_{3}$ using TMS as internal standard. EIMS spectra were obtained with a Finnigan Trace GCPolaris Q. spectrometer. Elementary analysis data were acquired from a Perkin Elmer Ser. II CHNS/0 2400 elementalanalyzer.

Chloro-aceticacid 1-(3-\{3-chloro-1-[2-(2-chloroacetylamino)-ethyl]-4-oxo-2-phenyl-azetidin-2-yl\}propyl)-4-(4-chloro-phenyl)-piperidin-4-yl ester (3). A solution of $1(100 \mathrm{mg}, 0.24 \mathrm{mmol})$, chloroacetyl chloride $(50 \mu \mathrm{l}, 0.63 \mathrm{mmol})$ and triethylamine ( $100 \mu \mathrm{l}, 0.71 \mathrm{mmol})$ in $5 \mathrm{~mL}$ of methanol was stirring for $72 \mathrm{~h}$ to room temperature. The reaction mixture was evaporated to a smaller volume. After the mixture was diluted with water and extracted with chloroform. The organic phase was evaporated to dryness under reduced pressure, the residue was purified by crystallization from methanol: water (3:1) yielding $69 \%$ of product, m.p. $98-100^{\circ} \mathrm{C}$; IR $\left(\mathrm{V}_{\max }, \mathrm{Cm}^{-1}\right): 1724,1712,1648,1210 ;{ }^{1} \mathrm{H}$ NMR (300 $\left.\mathrm{MHz}, \mathrm{CDCl}_{3}\right) \delta_{\mathrm{H}}: 1.64-1.79(\mathrm{~m}, 4 \mathrm{H}), 1.80(\mathrm{t}, 2 \mathrm{H}, \mathrm{J}$ $=7.47 \mathrm{~Hz}), 1.86-2.06(\mathrm{~m}, 2 \mathrm{H}), 2.48(\mathrm{t}, 2 \mathrm{H}, \mathrm{J}=7.8$ $\mathrm{Hz}), 2.80(\mathrm{~m}, 1 \mathrm{H}), 2.84(\mathrm{~m}, 2 \mathrm{H}), 2.88(\mathrm{~m}, 1 \mathrm{H}), 3.06$ $(\mathrm{m}, 2 \mathrm{H}), 3.84(\mathrm{t}, 2 \mathrm{H}, \mathrm{J}=6.03 \mathrm{~Hz}), 4.10(\mathrm{t}, 2 \mathrm{H}, \mathrm{J}$ $13.62 \mathrm{~Hz}), 4.30(\mathrm{t}, 2 \mathrm{H}, \mathrm{J}=14.80 \mathrm{~Hz}), 5.32(\mathrm{~m}, 1 \mathrm{H})$, $6.60($ broad, $1 \mathrm{H}), 7.02-7.30(\mathrm{~m}, 8 \mathrm{H}) \mathrm{ppm} .{ }^{13} \mathrm{C}$ NMR $\left(75.4 \mathrm{MHz}, \mathrm{CDCl}_{3}\right) \quad \delta_{\mathrm{C}}: 23.00(\mathrm{C}-8), 32.80$ (C-9), 33.98 (C-3, C-5), 35.39 (C-30), 42.00 (C-36), 42.40 (C-40), 46.90(C-2, C-6), 49.30 (C-29), 55.28 (C7), 70.78 (C13), 74.00 (C-10), 79.66 (C-4), 115.08 (C-25, C-27), 122.38 (C-24, C-28), 128.30(C-19, C-21), 128.50 (C-18, C-22),134.22 (C-20), 136.40 (C-23), 141.00(C-17), 161.68 (C-26), 162.58(C-32), 166.30(C-12), 167.28(C-15) ppm. El-MS m/z:644.10 $\left(\mathrm{M}^{+} 12\right)$. Anal. Calcd. for $\mathrm{C}_{29} \mathrm{H}_{32} \mathrm{Cl}_{4} \mathrm{FN}_{3} \mathrm{O}_{4}: \mathrm{C}, 53.80$; $\mathrm{H}, 4.98 ; \mathrm{Cl}, 21.90 ; \mathrm{F}, 2.93 ; \mathrm{N}, 6.49 ; \mathrm{O}, 9.89$. Found: C, 53.78; H, 4.96 .

2,4-Bis-(\{2-[4-[4-(4-chloro-phenyl)-4hydroxy-piperridin-1-yl]-1-(4-fluoro-phenyl)butylideneamino]-ethylimino\}-methyl)-13methyl-7,8,9,11,12,13,14,15,16,17-decahydro6H-cyclopenta[a]phenanthrene-3,17-diol (5)

A solution of 1 (100 mg, $0.24 \mathrm{mmol}), 4(160$ $\mathrm{mg}, 0.48 \mathrm{mmol}$ ) and boric acid (90 mg, 1.45mmol) in $5 \mathrm{~mL}$ of methanol was stirring for $72 \mathrm{~h}$ to room temperature. The reaction mixture was evaporated to a smaller volume. After the mixture was diluted with water and extracted with chloroform. The organic phase was evaporated to dryness under reduced pressure, the residue was purified by crystallization from methanol:water (3:2) yielding $48 \%$ of product, m.p. $112-114^{\circ} \mathrm{C}$; IR $\left(\mathrm{V}_{\max }, \mathrm{Cm}^{-1}\right): 3400,3320,1204,{ }^{1} \mathrm{H}$ $\operatorname{NMR}\left(300 \mathrm{MHz}, \mathrm{CDCl}_{3}\right) \delta_{\mathrm{H}}: 0.68(\mathrm{~s}, 3 \mathrm{H}), 0.80-1.40$ $(\mathrm{m}, 7 \mathrm{H}), 1.58-1.66(\mathrm{~m}, 8 \mathrm{H}), 1.70(\mathrm{~m}, 4 \mathrm{H}), 1.78-2.16$ $(\mathrm{m}, 5 \mathrm{H}), 2.46-2.52(\mathrm{~m}, 8 \mathrm{H}), 2.80(\mathrm{~m}, 4 \mathrm{H}), 2.96-2.98$ $(\mathrm{m}, 2 \mathrm{H}), 3.02(\mathrm{~m}, 4 \mathrm{H}), 3.03(\mathrm{~m}, 1 \mathrm{H}), 3.50(\mathrm{~m}, 4 \mathrm{H})$, $3.68(\mathrm{~m}, 1 \mathrm{H}), 3.76(\mathrm{~m}, 4 \mathrm{H}), 6.90-7.20(\mathrm{~m}, 12 \mathrm{H})$, $7.40(\mathrm{~m}, 1 \mathrm{H}), 7.84$ (broad, 4H), 7.98-8.08 (m, 2H), $8.16(\mathrm{~m}, 4 \mathrm{H}) \mathrm{ppm} .{ }^{13} \mathrm{C} \mathrm{NMR}\left(75.4 \mathrm{MHz}, \mathrm{CDCl}_{3}\right) \delta_{\mathrm{C}}$ : 
13.20 (C-59), 23.76 (C-27), 25.50 (C-20), 25.67 (C-31), 26.80 (C-8, C-64), 27.92 (C-21), 31.10 (C-26), 35.12 (C-9, C-63), 35.60 (C-32), 38.25 (C-68), 38.30(C-3, C-5, C-70), 38.86 (C-22), 44.32 (C-24), 46.18 (C-30), 47.00(C-2, C-6, C-67, C-71), 48.94(C-23), 52.44(C-12, C-50), 54.25 (C-7, (C65), 60.00 (C-13, C- 49), 70.00 (C-4, C-70), 81.24 (C-25), 110.76(C-18), 115.00 (C-42, C-44, C-55, C-57), 119.66(C-16), 126.84 (C-41, C-45, C-54, C-58), 128.52(C-36, C-38, C-76, C-78), 128.8 (C29), 129.10 (C-35, C-39, C-75, C-79), 134.98 (C-40, C-53), 135.60(C-28), 136.12(C-37, C-77), 145.14(C34, C-74), 149.78 (C-19), 158.70(C-17), 162.50 (C-47), 162.88(C-15), 163.84(C-43, C-56), 165.08 (C-10, C-52) ppm.El-MS m/z:1126.50 (M+10). Anal. Calcd. for $\mathrm{C}_{66} \mathrm{H}_{78} \mathrm{Cl}_{2} \mathrm{~F}_{2} \mathrm{~N}_{6} \mathrm{O}_{4}: \mathrm{C}, 70.26 ; \mathrm{H}, 6.97 ; \mathrm{Cl}$, 6.28; F, 3.37; N, 7.45; O, 5.67. Found: C, 70.22; $\mathrm{H}$, 6.96 .

Chloro-aceticacid 2,4-bis-[3-chloro-1-(2\{3-chloro-2-[4-[4-(2-chloro-acetoxy)-4-(4chlorophenyl)-piperidin-1-yl]-1-(4-fluorophenyl)-butyl]4-oxo-azetidin-1-yl\}-ethyl)-4oxo-azetidin-2-yl]-17-[(chlorocarbonyl)oxy]-13methyl-7,8,9,11,12,13,14,15,16,17-decahydro-6H-cyclopenta[a]phenanthren-3-yl ester (6)

A solution of $5(200 \mathrm{mg}, 0.18 \mathrm{mmol})$, chloroacetyl chloride $(50 \mu \mathrm{l}, 0.63 \mathrm{mmol})$ and triethylamine $(100 \mu \mathrm{l}, 0.71 \mathrm{mmol})$ in $5 \mathrm{~mL}$ of methanol was stirring for $72 \mathrm{~h}$ to room temperature. The reaction mixture was evaporated to a smaller volume. After the mixture was diluted with water and extracted with chloroform. The organic phase was evaporated to dryness under reduced pressure, the residue was purified by crystallization from methanol:water (3:1) yielding $86 \%$ of product, m.p. 98-100 $\mathrm{C}$; IR $\left(\mathrm{V}_{\max }, \mathrm{cm}^{-1}\right): 1722,1710,1206 ;{ }^{1} \mathrm{H}$ NMR $\left(300 \mathrm{MHz}, \mathrm{CDCl}_{3}\right) \delta_{\mathrm{H}}: 0.80(\mathrm{~s}, 3 \mathrm{H}), 1.18-1.50(\mathrm{~m}$, $6 \mathrm{H}), 1.66(\mathrm{~m}, 4 \mathrm{H}), 1.70(\mathrm{~m}, 4 \mathrm{H}), 1.72-1.76(\mathrm{~m}, 3 \mathrm{H})$, $1.79(\mathrm{~m}, 4 \mathrm{H}), 1.82(\mathrm{~m}, 2 \mathrm{H}), 1.90(\mathrm{~m}, 1 \mathrm{H}), 1.96(\mathrm{~m}$, $2 \mathrm{H}), 2.10-2.20(\mathrm{~m}, 2 \mathrm{H}), 2.40(\mathrm{~m}, 4 \mathrm{H}), 2.54-2.60(\mathrm{~m}$, $3 \mathrm{H}), 2.80-3.02(\mathrm{~m}, 8 \mathrm{H}), 3.40(\mathrm{~m}, 2 \mathrm{H}), 3.50-3.60(\mathrm{~m}$, $8 \mathrm{H}), 4.08(\mathrm{~m}, 2 \mathrm{H}), 4.12-4.30(\mathrm{~m}, 8 \mathrm{H}), 4.70-4.76(\mathrm{~m}$, $3 \mathrm{H}), 4.80(\mathrm{~m}, 1 \mathrm{H}), 4.90-5.70(\mathrm{~m}, 3 \mathrm{H})$, 6.78-7.22 (m, 17H) ppm. ${ }^{13} \mathrm{C}$ NMR $\left(75.4 \mathrm{MHz}, \mathrm{CDCl}_{3}\right) \mathrm{d}_{\mathrm{C}}: 11.78$ (C-68), 23.83 (C-53), 25.97 (C-57), 27.25 (C-52), 27.71 (C-47), 27.80 (C-8, C-86),), 28.16 (C-46), 31.10(C-9, C-85), 34.00(C-3, C-5, C-90, C-92),37.28 (C-58), 38.80 (C-48), 40.56 (C-72), 40.78 (C-82), 42.00 (C-38, C-112), 43.10 (C-50), 44.68 (C-30,
C-75), 45.04 (C-31, C-74), 46.10 (C-56), 46.50 (C-10, C-84), 47.00(C-2, C-6, C-89, C-93), 51.24 (C-49), 55.28(C-7, C-87), 60.40 (C-14, C-78), 61.32 (C-64),62.66 (C-64), 63.10 (C-67), 64.80(C-33), 71.44 (C-11, C-77), 79.22 (C-4, C-91),81.64 (C-51), 114.65 (C-26, C-28, C-100), 126.18 (C-54), 126.30 (C-42), 128.28(C-20, C-22, C-107, C-109), 128.50 (C-19, C-23, C-106, C-110),130.83 (C-25, 131.97 C-29, C-9), C-106), 131.10 (C-24, C-96), 132.38 (C-44), 134.30(C-21, C-108), 135.53 (C-45), 140.61 (C-18, C-105), 141.66(C-43), 143.79 (C-55), 160.10 (C-27, C-99), 166.00(C-13, C-79), 166.20 (C-35, C-66), 167.25(C-16, C-103), 168.00 (C-70), 168.16 (C-62) ppm. El-MS m/z: 1762.30(M+8). Anal. Calcd. for $\mathrm{C}_{84} \mathrm{H}_{90} \mathrm{Cl}_{10} \mathrm{~F}_{2} \mathrm{~N}_{6} \mathrm{O}_{12}: \mathrm{C}, 57.06 ; \mathrm{H}, 5.13 ; \mathrm{Cl}, 20.05$; F, 2.15; N, 4.75; O, 10.86. Found: C, 57.04; H, 5.10.

\section{RESULTS AND DISCUSSION}

In this study is reporteda straight forward route for synthesis of two azetidin-haloperidol derivatives using some strategies. The first stage was achieved by the synthesis of $1-(3-\{3-c h l o r o-$ 1-[2-(2-chloro-acetylamino)-ethyl]-4-oxo-2-phenylazetidin-2-yl\}-propyl)-4-(4-chloro-phenyl)-piperidin$4-y l$ ester(3) by the reaction of $\mathbf{1}$ with chloroacetyl chloride using triethylamine as catalyst. It is important to mention that this method has been previously reported for other type of compound with animino group involved in its structure chemical, which react with chloroacetyl chloride to form an azetine group in presence of triethylamine ${ }^{10}$. However, it is noteworthy that amino group of compound 3also reacting with chloroacetyl chloride to form a new chloroamide group; this method is different to several previously reported procedures for thechloroamides formation ${ }^{11,12}$. The ${ }^{1} \mathrm{H}$ NMR spectrum of the 3 shows signals at1 1.64-1.79, 2.84 and $3.06 \mathrm{ppm}$ for piperidine group; at 1.80-2.48 ppm for methylene groups bound to both piperidine and azetidinegroups; at 2.80, 3.84 for methylene groups bound to both azetidine and amide groups; at $4.10 \mathrm{ppm}$ for methylene group bound to chloroacetamide group; at $4.30 \mathrm{ppm}$ for methylene group bound to ester group; at 5.32 ppm for proton involved in the azetidinering; at 6.60 ppm for amide group; at 7.02-7.30 ppm for phenyl groups. The ${ }^{13} \mathrm{C}$ NMR spectra displays chemical shifts at23.00, 32.80 and $55.28 \mathrm{ppm}$ for methylene groups bound to piperidine and azetidine groups, at 33.98, 46.90 and $79.66 \mathrm{ppm}$ for piperidine group; at 35.30 

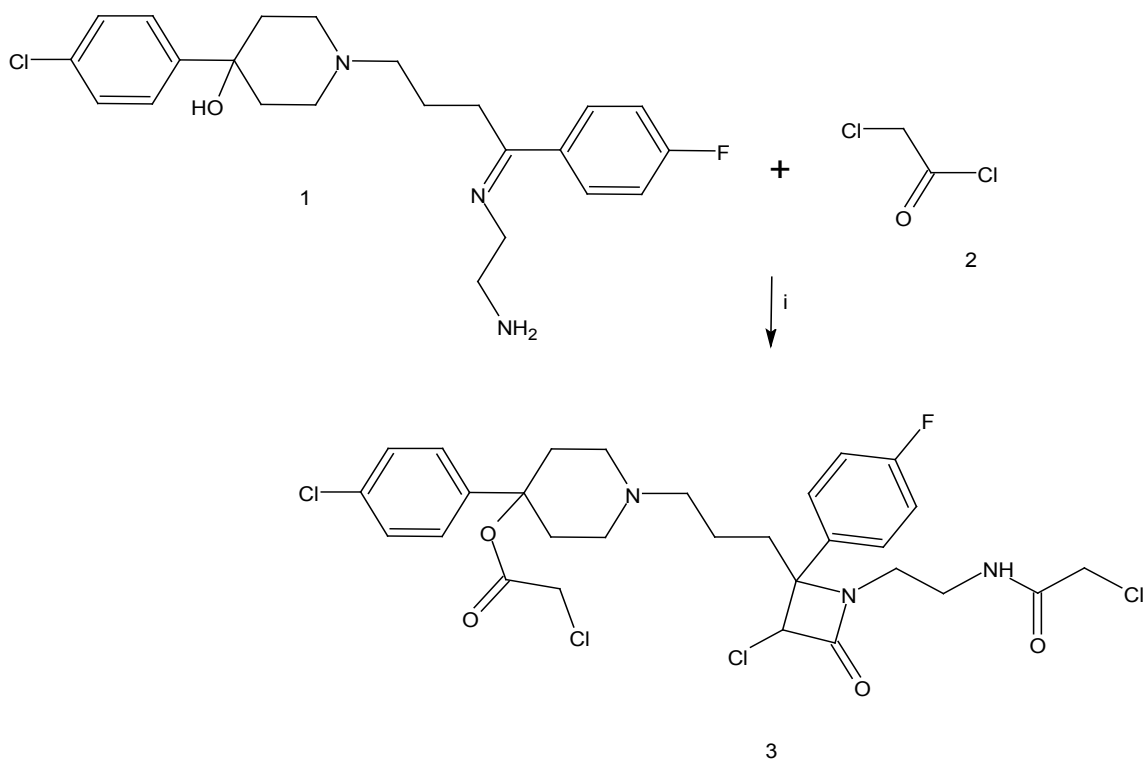

Fig. 1: Synthesis of Chloro-aceticacid 1-(3-\{3-chloro-1-[2-(2-chloro-acetylamino)-ethyl]-4-oxo-2phenyl-azetidin-2-yl\}-propyl)-4-(4-chloro-phenyl)-piperidin-4-yl ester (3).Reactionof1-[4-(2-Aminoethylimino)-4-(4-fluorocyclohexyl)-butyl]-4-(4-chloro-phenyl)-piperidin-4-ol (1) with chloroacetyl chloride (2) usingtriethylamine as catalyst (i)

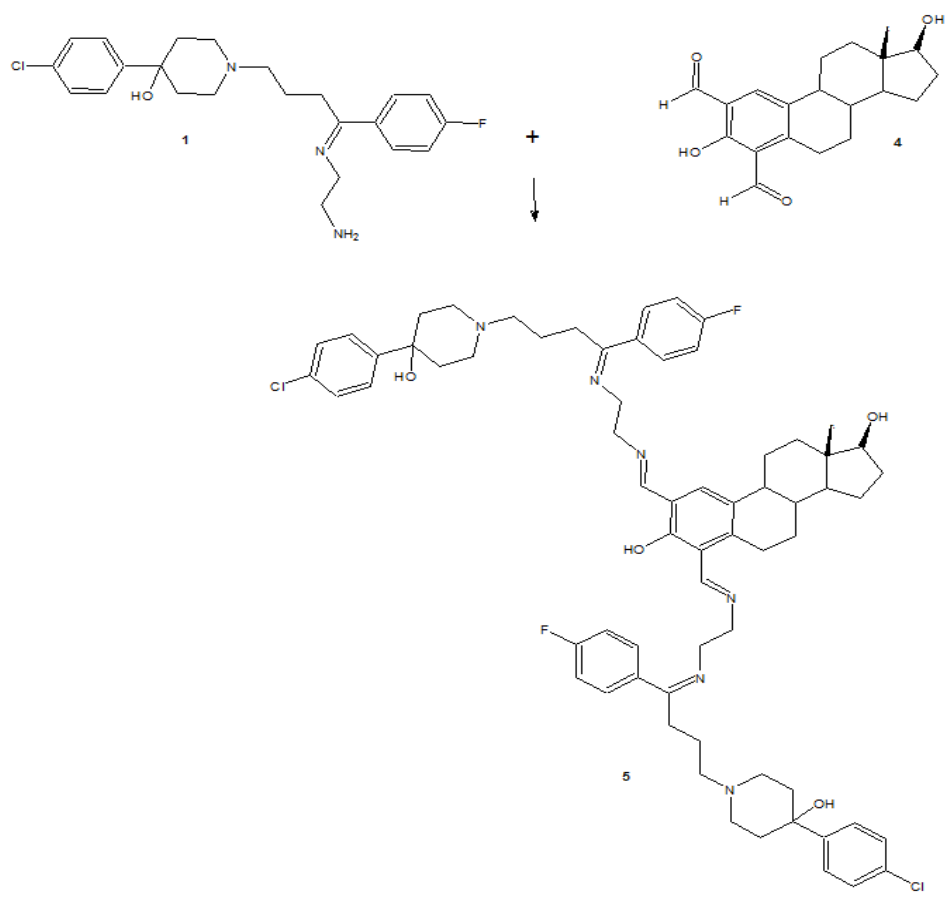

Figure 2. Synthesis of 2,4-Bis-(\{2-[4-[4-(4-chloro-phenyl)-4-hydroxy-piperridin-1-yl]-1(4-fluoro-phenyl)-butylideneamino]-ethylimino\}-methyl)-13-methyl-7,8,9,11,12,13,14,15,16, 17-decahydro-6H-cyclopenta[a]phenanthrene-3,17-diol (5). Reactionof1 with3,17-Dihydroxy-13methyl-7,8,9,11,12,13,14,15,16,17-decahydro-6H-cyclopenta[a]phenanthrene-2,4-dicarbaldehyde (4)tosynthesisof5 usingboricacid as catalyst (ii) 
and $49.30 \mathrm{ppm}$ for methylene bound to both azetidine and amide groups, at 42.00 ppm for methylene group bound to ester group; at $42.40 \mathrm{ppm}$ for methylene group bound to chloroacetamide group; at 70.78 and $74.00 \mathrm{ppm}$ for carbons involved in the azetidine group;at 115.08-161.68 ppm for phenyl groups; at $162.58 \mathrm{ppm}$ for amide group; at $166.30 \mathrm{ppm}$ for ketone group; at $167.28 \mathrm{ppm}$ for ester group. Finally, the presence of $\mathbf{3}$ was further confirmed from mass spectrum which showed a molecular ion at m/z 644 .

The second stage was achieved by reaction of 1 with an estradiol derivative to form the compound5. It is important to mention there are several reports which indicate the synthesis of imino groups; nevertheless, expensive reagents and special conditions are required ${ }^{13}$. In this study, boric acid was used as catalyst to formation of imino group involved in the chemical structure of
5. ${ }^{1} \mathrm{H}$ NMR spectrum of the 5 shows signals at0.68 ppm for methyl group; at 0.80-1.40, 1.78-2.16, 2.96$2.98,3.03,3.68$ and 7.40 ppm for steroid moiety; at 1.58-1.66, 2.80 and 3.02 ppm for piperidine groups; at 1.70 and $2.46-2.52 \mathrm{ppm}$ for methylene groups bound to both piperidine rings; at 3.50 and 3.76 ppm for methylene groups bound to imino groups; at 7.84 ppm for hydroxyl groups; at 6.90-7.20 and 8.16 ppm for phenyl groups; at 7.98-8.08 ppm for imino groups. The ${ }^{13} \mathrm{C}$ NMR spectra displays chemical shifts at13.20 ppm for methyl group bound to steroid nucleus; at 23.76-25.67, 27.92-31.10, 35.60, 38.86$46.18,48.94,81.24-110.76,119.66,128.80,135.60$ and 149.78-158.70 ppm for steroid moiety; at 26.80, 35.12 and $54.25 \mathrm{ppm}$ for methylene groups bound to piperidine ring; at 52.44 and 60.00 ppm for methylene groups bound to both imine groups; at 38.25-38.30 and $47.00-70.00 \mathrm{ppm}$ for piperidine ring; at 162.50162.88 and 165.08 ppm for imino groups; at 115.00,

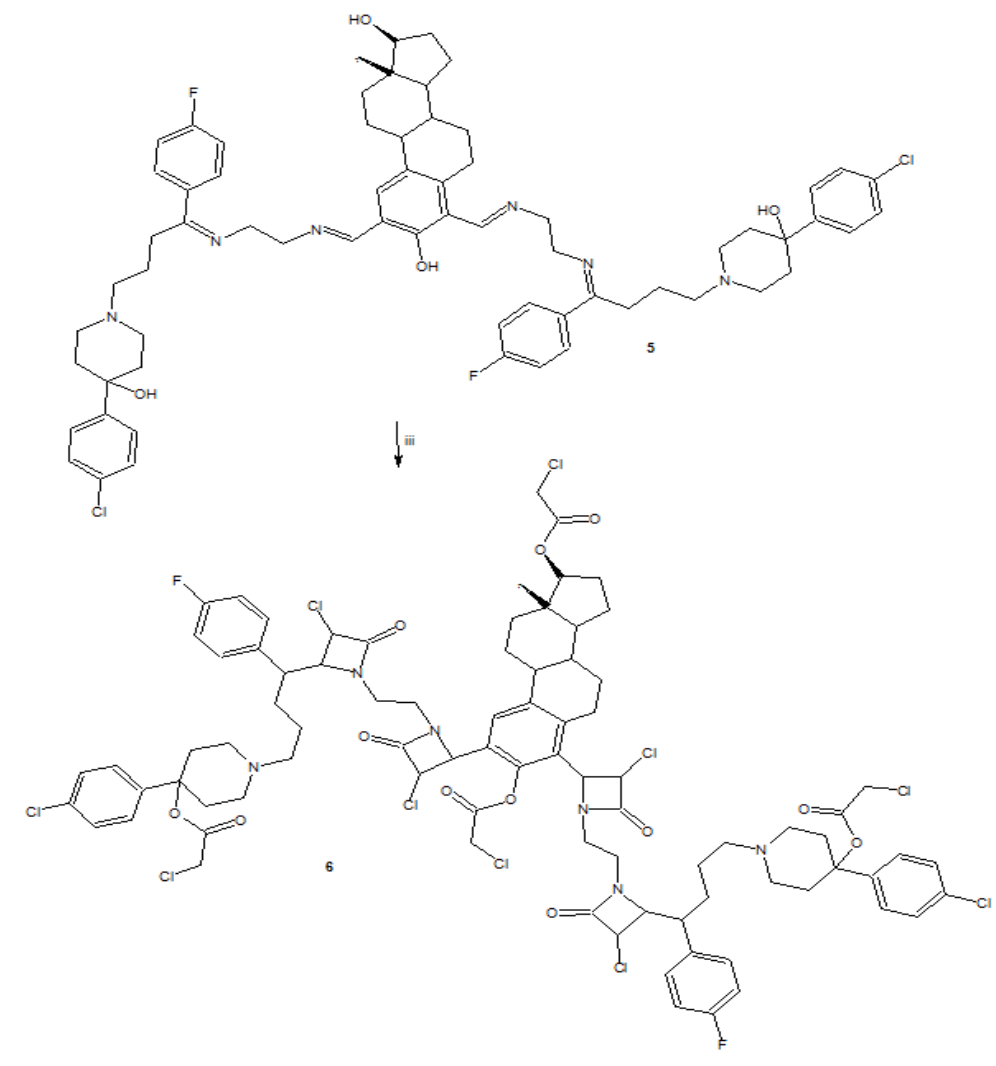

Fig. 3: Synthesis of Chloro-aceticacid 2,4-bis-[3-chloro-1-(2-\{3-chloro-2-[4-[4-(2-chloro-acetoxy) -4-(4-chlorophenyl)-piperidin-1-yl]-1-(4-fluoro-phenyl)-butyl]4-oxo-azetidin-1-yl\}-ethyl)-4oxo-azetidin-2-yl]-17-[(chlorocarbonyl)oxy]-13-methyl-7,8,9,11,12,13,14,15,16,17-decahydro6-H-cyclopenta[a]phenanthren-3-yl ester (6).Reactionof5withchloroacetyl chloride (2) usingtriethylamine as catalyst (iii) 
126.84-128.52, 129.10-134.98, 136.12-145.14 and $163.84 \mathrm{ppm}$ for phenyl groups. Finally, the presence of 5 was further confirmed from mass spectrum which showed a molecular ion at $\mathrm{m} / \mathrm{z} 1126.50$.

The third stage was achieved by the preparation of an azetine-steroid derivative (6) by the reaction of 5 with chloroacetylchloride to form an azetine groupinvolved in the compound 6 using triethylamine as catalyst. The ${ }^{1} \mathrm{H}$ NMR spectrum of the 6 shows signals at $0.80 \mathrm{ppm}$ for methyl group; at 1.18-1.50, 1.72-1.76, 1.90, 2.10-2.20,, 2.54-2.60 and $4.80 \mathrm{ppm}$ for steroid nucleus; at $1.66,1.82$, 1.96 , and $2.40 \mathrm{ppm}$ for methylene groups bound to both piperidine and phenyl groupsat 1.70, 1.79, 2.80-3.02 ppm from both piperidine rings; at 3.40 ppm for methylene groups bound to both phenyl and azetidine; at 3.50-3.60 ppm for methylene bound to azetidine groups; at 4.12-4.30 ppm for methylene bound to ester groups; at 4.08, 4.704.76, 4.90-5.70 ppm for protons involved in the azetidine rings; at 6.78-7.22 ppm for phenyl groups. The ${ }^{13} \mathrm{C}$ NMR spectra displays chemical shifts at $11.78 \mathrm{ppm}$ for methyl group; at 23.83-27.71. 28.16, 37.28-38.80, 43.10, 46.10, 51.24, 81.64, 126.18-126.30, 132.38, 135.53 and $141.36-143.79 \mathrm{ppm}$ for steroid moiety; at $27.80,31.10$ and $55.28 \mathrm{ppm}$ for methylene groups bound to both phenyl and piperidine groups; at $34.00,47.00$ and $79.22 \mathrm{ppm}$ for piperidine ring; at 40.56-42.00 for methylene groups bound to ester groups; at $60.40-71.44,166.00$ for azetidine rings; at $44.68-45.04 \mathrm{ppm}$ for methylene groups bound to azetidine rings; at $46.50 \mathrm{ppm}$ for methylene bound to both phenyl and azetidine groups; at 114.65 , 128.28-131.10, 134.30, 140.61 and $160.10 \mathrm{ppm}$ for phenyl groups; at 167.25 and $168.16 \mathrm{ppm}$ for ester groups; at 166.00-166.20 for ketone groups. Finally, the presence of 6 was further confirmed from mass spectrum which showed a molecular ion at $\mathrm{m} /$ z1762.30.

\section{REFERENCES}

1. Yadav, D.; Awasthi, C.; Rai, V.; Rai, A. 8. Tetrahedron Lett. 2007, 48, 8037-8039.

2. Isoda, T.; Yakamura, I.; Tamai, S.; Kumagai, T.; Nagao, Y. Chem. Pharm. Bull. 2006, 10, 1408-1411.

3. Manhas, m., Bari, S.; Bhawal, B.,; Bose, A. Tetrahedron Lett. 1984, 25, 4733-4736.

4. Barluenga, J.; Fernandez, F.; Viado, A.; Aguilar, A.; Olano, B. Org. Chem. 1996, 61, 5659-5662.

5. Frigola, J.; Torrens, A.; Castrillo, J.; Mas, J.; Vafi, D.; Berrocal, J.; Calvet, C.; Salgado, L. J. Med. Chem. 1994, 37, 4195-4210.

6. Sonwane, S .; Srivastava, S.; Srivastava, S. Indian J. Chem. 2008, 47B, 633-636.

7. Dai, S.; Tzong-Yuan J.; Chih-Ping, C.; HsinYu, C.; Wen-Jang, Kuo.; Wen-Chiung, S.; Ru-Jong, J. J. Appl. Polymer Sci. 2007, 103, 3591-3599.
8. Figueroa-Valverde, L.; Díaz-Cedillo, F.; GarcíaCervera, E.; Pool-Gómez, E.; López-Ramos, M.; Rosas-Nexticapa, M.; Hau-Heredia, L.; Sarabia-Alcocer, B.; Velázquez-Sarabia, B. M. BioMed Res. Inter. 2014, http://dx.doi. org/10.1155/2014/217865.

9. Figueroa-Valverde, L.; Díaz-Cedillo, F.; LópezRamos, M.; García-Cervera, E.; Pool-Gómez, E. African J. Pharmacy Pharmacol. 2011, 5, 1703-1712.

10. Hui-Ling, L.; Zongcheng, L.; Thorleif, A. Molecules. 2000, 5, 1055.

11. Martin, A.; Sanchez-Chaves, M.; Arranz, F. Reac. Func. Polym. 1999, 39, 179-187.

12. Bai, F.; Li, R.;Yang, X.; Li S. Polymer. Int. 2006 , 55, 319-325.

13. Hania, M. E-J Chem. 2009, 6, 629-632. 